\title{
Systematic analysis of alternative first exons in plant genomes Wei-Hua Chen ${ }^{\dagger 1}, 4$, Guanting Lv ${ }^{\dagger 1}{ }^{1}$, Congying Lv ${ }^{3}$, Changqing Zeng ${ }^{1}$ and Songnian $\mathrm{Hu}^{* 1}$
}

Address: ${ }^{1}$ Key Laboratory of Genome Science and Information, Beijing Institute of Genomics, Chinese Academy of Sciences, Beijing, China, ${ }^{2}$ Graduate School of Chinese Academy of Sciences, Beijing, China, ${ }^{3}$ Nanyang Institute of Technology, Henan, China and ${ }^{4}$ Bioinformatics, Heinrich-Heine-University, Duesseldorf, Germany

Email: Wei-Hua Chen - chenwh550@gmail.com; Guanting Lv - lvgt@genomics.org.cn; Congying Lv - Alin0378@SOHU.com; Changqing Zeng - czeng@genomics.org.cn; Songnian Hu* - husn@genomics.org.cn

* Corresponding author †Equal contributors

Published: 17 October 2007

BMC Plant Biology 2007, 7:55
Received: 17 February 2007

Accepted: 17 October 2007

\section{(c) 2007 Chen et al; licensee BioMed Central Ltd.}

This is an Open Access article distributed under the terms of the Creative Commons Attribution License (http://creativecommons.org/licenses/by/2.0), which permits unrestricted use, distribution, and reproduction in any medium, provided the original work is properly cited.

\begin{abstract}
Background: Alternative splicing (AS) contributes significantly to protein diversity, by selectively using different combinations of exons of the same gene under certain circumstances. One particular type of AS is the use of alternative first exons (AFEs), which can have consequences far beyond the fine-tuning of protein functions. For example, AFEs may change the $\mathrm{N}$-termini of proteins and thereby direct them to different cellular compartments. When alternative first exons are distant, they are usually associated with alternative promoters, thereby conferring an extra level of gene expression regulation. However, only few studies have examined the patterns of AFEs, and these analyses were mainly focused on mammalian genomes. Recent studies have shown that AFEs exist in the rice genome, and are regulated in a tissuespecific manner. Our current understanding of AFEs in plants is still limited, including important issues such as their regulation, contribution to protein diversity, and evolutionary conservation.

Results: We systematically identified I,378 and 645 AFE-containing clusters in rice and Arabidopsis, respectively. From our data sets, we identified two types of AFEs according to their genomic organisation. In genes with type I AFEs, the first exons are mutually exclusive, while most of the downstream exons are shared among alternative transcripts. Conversely, in genes with type II AFEs, the first exon of one gene structure is an internal exon of an alternative gene structure. The functionality analysis indicated about half and $\sim 19 \%$ of the AFEs in Arabidopsis and rice could alter $\mathrm{N}$-terminal protein sequences, and $\sim 5 \%$ of the functional alteration in type II AFEs involved protein domain addition/deletion in both genomes. Expression analysis indicated that $20 \sim 66 \%$ of rice AFE clusters were tissue- and/or development- specifically transcribed, which is consistent with previous observations; however, a much smaller percentage of Arabidopsis AFEs was regulated in this manner, which suggests different regulation mechanisms of AFEs between rice and Arabidopsis. Statistical analysis of some features of AFE clusters, such as splice-site strength and secondary structure formation further revealed differences between these two species. Orthologous search of AFE-containing gene pairs detected only 19 gene pairs conserved between rice and Arabidopsis, accounting only for a few percent of AFE-containing clusters.

Conclusion: Our analysis of AFE-containing genes in rice and Arabidopsis indicates that AFEs have multiple functions, from regulating gene expression to generating protein diversity. Comparisons of AFE clusters revealed different features in the two plant species, which indicates that AFEs may have evolved independently after the separation of rice (a model monocot) and Arabidopsis (a model dicot).
\end{abstract}




\section{Background}

Alternative splicing (AS) is an important mechanism, which contributes greatly to protein diversity by selectively using different sets of exons of one gene in different tissues or cells under certain circumstances [1-3]. It has been shown to exist in nearly all metazoan organisms, and was estimated to involve $30-70 \%$ of human genes $[4,5]$. However, AS variants identified so far are biased towards alternative exons that include coding sequences (CDSs) [6]. Actually, many AS isoforms use alternative first exons (AFEs) to regulate their expression and generate protein diversity. An AFE is the first exon of one splice isoform of a gene, but either located downstream of a corresponding AFE of other isoforms generated by the same gene, or absent from other isoforms altogether. It has been reported that this phenomenon also contributes to the complexity of gene expression $[6,7]$.

To date, studies of AFEs have been focused mainly on mammalian genomes, especially mouse and human. It has been reported that of the full-length genes in the RIKEN databases, about $9 \%$ contained AFEs in mouse [8] and more than $18 \%$ contained AFEs in human [9]. AFEs could be produced by alternative promoter usage. Some AFEs merely change the 5 '-untranslated region (5'-UTR) to exert regulation on translational efficiency or the efficiency or destination of the transcripts' transportation out of the nucleus. In this case, the shared downstream exons contain the translation start codons (ATGs), and thus have the same open reading frames (ORFs) and produce identical proteins [6,10-12]. In other cases, AFEs contain alternative transcription start sites (ATGs), which could result in protein variants that differ in the $\mathrm{N}$-termini $[2,13,14]$ or in novel proteins $[15,16]$.

Up until now, only few studies have analyzed AFEs in plants. For example, SYN1 in Arabidopsis was shown to produce two isoforms with distinct alternative first exons [17]. Recently, a large-scale study of AFEs in rice has discovered 46 potential AFE-containing clusters, and has shown their involvement in tissue-specific transcription [14]. But our knowledge about AFEs in plants is still limited. Here, we used a systematic approach to analyze their contribution to protein diversity and their evolutionary conservation between rice (a model monocot) and Arabidopsis thaliana (a model dicot).

\section{Methods}

\section{Systematic detection of AFEs in plant genomes}

To compile our AFE data sets, we downloaded the following data sets of rice (Oryza sativa L. ssp. Japonica) and Arabidopsis from public databases: full-length cDNAs, expressed sequence tags (ESTs), reference sequences (NCBI refseq) and mRNAs (Table 1). Genome location and exact gene structure were determined for each of the cDNA sequences using the GMAP program [18]. We excluded sequences that showed low similarities with the genome sequence $(<95 \%$ identities and $<90 \%$ coverage for reference genes and full-length cDNAs; $<90 \%$ identities and $<90 \%$ coverage for ESTs), did not map onto a unique genomic region, or were derived from organelles (mitochondrion and chloroplast). All information was loaded into MySQL databases for further analysis.

We first grouped full-length cDNAs and reference genes into clusters on the genome if they mapped onto the same genomic region, were orientated on the same strand, and had overlapping sequences. Within each cluster, members were further grouped according to their gene structures. ESTs were then added into the existing clusters. An EST was either added as a member of an existing gene structure, or as a new gene structure in a cluster according to the location of the first exon on the genome. ESTs that could not be grouped into a unique gene structure in one cluster were discarded. After adding ESTs, we counted the number of ESTs for each gene structure in each cluster. To produce reliable results, we discarded gene structures that consisted of only one EST.

Table I: Acquired data

\begin{tabular}{llll}
\hline Species & Sequence & Datasets & Database \\
\hline Oryza sativa L. ssp. Japonica & General EST & $1,211,078$ & NCBI dbEST \\
& mRNA & 23,309 & NCBI CoreNucleotide \\
& Full-length cDNA & 32,127 & KOME** \\
& Genome & & IRGS* Release 4.0 \\
Arabidopsis thaliana & General EST & 734,275 & NCBI dbEST \\
& mRNA & 30,476 & NCBI CoreNucleotide \\
& Full-length cDNA & 15,294 & RIKEN RAFL*** \\
& Genome & & NCBI Genomes \\
\hline
\end{tabular}

*IRGSP stands for International Rice Genome Sequencing Project

**KOME stands for Knowledge-based Oryza Molecular biological Encyclopedia

*** RAFL stands for RIKEN Arabidopsis Full-length cDNA clones 
Since only full-length cDNAs in our data sets could guarantee the reliability of transcription start sites (TSSs) and the first exons, we searched for AFEs in clusters that contained full-length cDNAs and had at least two distinct gene structures. We defined the first exon of a cluster as the 5'-most of all first exons among gene structures that contained full-length cDNAs. Then other gene structures in the same cluster were compared with this first exon to identify possible AFEs.

Within each AFE-containing gene cluster, we determined major and minor types of alternative first exons by calculating numbers of their supporting ESTs. A first exon type was marked as 'major' type if it had more supporting ESTs than any other first exon in the cluster; else it was marked as 'minor'.

\section{Statistical analysis of AFEs}

Based on the alignment positions of AFEs, we determined the chromosomal distribution of AFE clusters in rice and Arabidopsis.

To identify possible factors that govern splicing sites selection in AFEs, such as splicing site strength, common motifs around splicing junctions, and secondary RNA structure formation around the splicing site, we performed the following statistical analyses of AFEs in rice and Arabidopsis. First, we examined splicing site quality of alternatively spliced first exons. By using exon annotations from GMAP, we extracted a 500-basepair window centered on each donor (5') splice site with sufficient flanking sequence, and used these data as input sequences to GeneSplicer [19] for splice site prediction.

Second, we analyzed whether AFEs tend to form secondary structures around splicing sites, which might potentially block the proper recognition of splice site signals and might thereby result in the skipping of the corresponding exon/intron. We used the program RNAfold of the Vienna RNA package [20] to predict folding for a 100basepair window centered on each splicing site. The minimal folding energy (MFE, also known as optimal folding energy, OFE) was calculated for each input sequence. A lower MFE score indicates that the input sequence is more likely to form secondary structures.

Third, we used MEME [21] to search for possible common motifs shared by all or a subset of alternatively spliced exons and neighboring intron sequences.

\section{Annotation and functional classification of AFE-containing clusters}

To annotate AFE-containing clusters, we compared either the reference gene or the longest full-length cDNA (if there was no reference sequence available) in each cluster with protein sequences in the Uniprot database [18] using BLAST-based tools. GO (Gene Ontology) terms were assigned according to Uniprot2GO associations downloaded from the website of the GeneOntology Consortium [22]. GO annotations were plotted using a webbased tool, WEGO [23]. Statistical significance of each GO category that was enriched or depleted among AFE-containing clusters was evaluated by calculating the hypergeometric distribution using the following equation:

$$
p=f(x \mid M, K, n)=\frac{\left(\begin{array}{l}
K \\
x
\end{array}\right)\left(\begin{array}{l}
M-K \\
n-x
\end{array}\right)}{\left(\begin{array}{l}
M \\
n
\end{array}\right)}
$$

Where $M=$ total genes classified by GO in an organism, $K$ $=$ number of genes classified by a specific GO category, $n$ $=$ total number of AFE-containing clusters classified by GO, $x=$ number of AFE-containing clusters classified by a specific GO category, and $p=$ probability that a GO category is significantly enriched or depleted.

Tissue-specific expression of AFEs in rice and Arabidopsis For the reliable detection of the tissue specificity of certain AFE isoforms, we adopted a strategy proposed by Qiang Xu et al. [5], namely 'tissue specificity scoring'. To this end, tissue specificity was measured by a tissue specificity score TS and two robustness values $r \mathrm{TS}$ and $r \mathrm{TS} \sim$ (for details see Ref. [5]). High confidence (HC) tissue specificity was defined as TS $>50, r \mathrm{TS}>0.9$ and $r \mathrm{TS} \sim>0.9$, and low confidence (LC) was defined as TS $>0, r \mathrm{TS}>0.5$ and $r \mathrm{TS} \sim>0.5$.

\section{Cross-genome comparison of AFEs-containing orthologous genes}

Orthologous relationship between rice and Arabidopsis were identified by using Inparanoid [24] with default parameter settings and with the Bootstrap option enabled. The output was parsed using a PERL script. Only genes that produced Bootstrap score $=100 \%$ were considered as orthologous.

\section{Functionality of AFE-containing clusters}

We used the tool GetORF in the EMBOSS software package [25] to find putative open reading frames for every AFE-containing cluster. To assess the potential of AFEs to produce protein diversity, we divided the AFE-containing structures into three groups: i) AFEs in a certain cluster were not involved in the ORF and the downstream exons resulted in the same ORF for all AFEs; ii) AFEs contained alternative transcription start sites (ATG), but the downstream exons were identical; iii) AFEs contained alternative transcription start sites and the downstream exons were not identical. 
In order to check if an AFE-containing structure generated transcripts containing premature stop codons (PTC) and could thus be degraded by nonsense-mediated decay mechanisms (NMD), the distance between the stop codon and the last 3 ' exon-exon junction was calculated. The NMD candidate was defined according to the $50 \mathrm{nt}$ rule, as previously suggested [26]: If the measured distance was $>50 \mathrm{nt}$, the AFE-containing structure was regarded as an NMD candidate.

\section{Results and discussion}

\section{Systematic identification of AFEs in plant genomes}

Based on comparisons of sequences from a large set of public databases, we identified 23,500 and 12,964 fulllength-cDNA containing gene clusters in rice and Arabidopsis, respectively. These gene clusters represented about $42 \%$ (out of 55,890 gene loci from the TIGR Rice Genome Annotation Release 4 ) and $48.5 \%$ (out of 26,751 protein coding genes from the TAIR Arabidopsis Genome Annotation Release 6) of the total expressed genes in rice and Arabidopsis, respectively. From this data, we identified 1,378 and 645 AFE-containing clusters in rice and Arabidopsis clusters, respectively. In rice, $\sim 5.9 \%$ of the expressed genes displayed AFE events. Compared with a recent estimate of $\sim 4 \%$ based on $5^{\prime}$-end ESTs [14], which were obtained from CAP-technology-based cDNA libraries, our AFE ratio is slightly higher. This increase may result from i) our much larger collection of full-length cDNAs and general 5 '-end ESTs, and/or ii) our potentially more sensitive detection method. In Arabidopsis, we observed a similar ratio ( $\sim 5 \%)$ of expressed genes that contained AFE events.

Based on the genomic positions of the first exons in a cluster, two patterns of AFEs were observed. Type I AFEs included those where the first exons were mutually exclusive and where most of the downstream exons were identical between gene structures within the same cluster (Figure 1A); Type II AFEs included those where the first exon of gene structure $A$ existed as an internal exon of gene structure $\mathrm{B}$ (Figure 1B). It should be noted that sometimes a cluster could contain more than one type of AFEs.

From our data sets, Type II was the most abundant type of AFEs. Type II accounted for $90 \%(1,241$ out of 1,378$)$ of all the AFE events in rice, and $83 \%$ (546 out of 645 ) in Arabidopsis (Table 2). The average distance between the start sites of alternative first exons was 1,644 bp in Arabidopsis, and 1,141 bp in rice. Using the $>500 \mathrm{bp}$ interval proposed by Kouichi Kimura et al. [6] as a criterion, we estimated that at least 257 and 352 of the Type II AFE evens in rice and Arabidopsis, respectively, resulted from alternative use of different core promoters. By applying the same criterion to type I AFE events, we identified an additional 62 and 22 putative alternative promoter (PAP)derived gene structures in rice and Arabidopsis, respec-
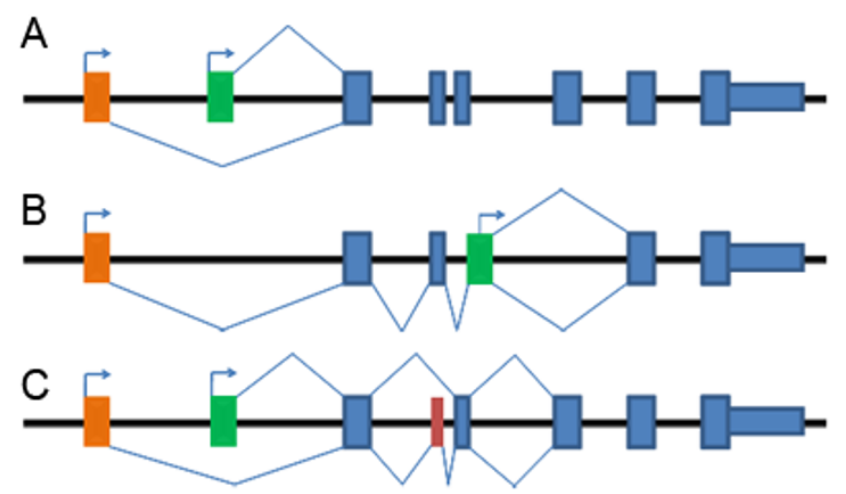

Figure I

Diagrammatic view of different types of AFE events. Alternative first exons are highlighted in orange and green. Constitutive exons are drawn in dark blue. Other alternatively spliced exons are drawn in brown. (A). Type I AFE clusters. Alternative first exons are mutually exclusive in different gene structures. (B). Type II AFE clusters. The first exon of one transcript is (part of) a downstream exon of other transcripts. (C). Some AFEs are coupled with downstream alternative splicing events.

tively. Although we could not determine the exact transcription start sites (TSSs) for non-full-length cDNA containing gene structures, our data suggested that the derived putative TSSs probably reflected true TSSs in vivo, as gene structures in each AFE cluster were supported by multiple general 5'-end ESTs from multiple cDNA libraries. Thus, we estimate that about $\sim 23 \%$ and $\sim 58 \%$ of AFEcontaining gene structures were derived from alternative promoters in rice and Arabidopsis, respectively.

\section{Statistical characterization of AFEs in plant genomes}

As shown in Figure 2, we detected no significant bias in the chromosomal distribution of AFEs in Arabidopsis. We also compared the distribution with relative gene density from the TAIR genome annotation, and did not detect any significant regional enrichment or depletion within chromosomes. A similar trend was also observed in the rice genome (see Additional File 1).

It is well documented that splice site strength plays important roles in splice-site selection and alternative splicing in mammalian genomes. Sequence composition around splice sites and its base pairing with the small nuclear RNA $\mathrm{U} 1$ regulate the inclusion rate of corresponding exons. To study whether similar mechanisms apply to plant genomes, we analyzed the 5' splice site (5'ss) strength of AFEs and compared it with that of constitutively spliced exons. As shown in Table 3, the results indicate that the 5 'ss of type I AFEs is relatively weak compared to constitutive exons, in both rice and Arabidopsis. However, when taking the exon inclusion rate into account, we found sig- 
Table 2: Results of AFE analysis in rice and Arabidopsis

\begin{tabular}{llll}
\hline & & Rice & Arabidopsis \\
\hline Type I AFE & & 137 & 99 \\
& N-terminal diversification & 53 & 20 \\
& Overlapping with functional domain & 5 & 1 \\
& Putative alternative promoter & 62 & 22 \\
& Both N-terminal and PAP & 3 & 7 \\
& NMD & 47 & 10 \\
\hline \multirow{2}{*}{ Type II AFE } & & 1,241 & 546 \\
& N-terminal diversification & 213 & 298 \\
& Overlapping with functional domain & 56 & 71 \\
& Putative alternative promoter & 257 & 352 \\
& Both N-terminal and PAP & 189 & 244 \\
& NMD & 237 & 42 \\
\hline \multirow{2}{*}{ Total } & & 1,378 & 645 \\
\hline
\end{tabular}

nificant differences between the two genomes. In Arabidopsis, the 5'ss strength of the major expressed AFE isoforms showed no statistical difference compared with that of constitutive exons (T-Test with $p<0.01$ ), while the minor AFE isoform differed significantly from the constitutive exon in splice site strength ( $p=3.2361 \mathrm{e}-012$, Table $3)$. Conversely, in rice we observed similar 5 'ss strengths between major and minor AFE isoforms. The analysis of type II AFEs revealed similar differences between rice and Arabidopsis: the 5 'ss strength in both major and minor type II AFE isoforms of Arabidopsis was similar to that of constitutive exons, while the 5 'ss strength of major AFE isoforms of rice was much lower compared to minor isoforms. These results suggest that different mechanisms are likely involved in the regulation of splicing-site selection or recognition in rice and Arabidopsis.

We further investigated the tendency to form secondary structures of sequences surrounding the 5 'ss of AFEs, as such structures were previously suggested to be able to regulate splice site recognition and splicing. We measured minimal folding energy (MFE) for a 100-base window centred on each 5 'ss for AFEs as well as constitutive exons. As shown in table 4, the results indicated that AFEs of Arabidopsis were less likely to form secondary structures at the 5 'ss compared to constitutive first exons, while AFEs in rice were significantly more likely to form secondary structures.

To investigate possible sequence motifs that might regulate the alternative use of first exons, we searched the sequences of AFEs and surrounding introns using the MEME program. Using a cutoff of $1 \mathrm{E}-5$ for sequence alignments, we did not detect significantly enriched motifs in all or subsets of AFEs and surrounding sequences. This result indicates that either some regulatory sequences were too degenerative to be detected using MEME, or AFEs are regulated by other mechanisms than specific sequence motifs.

\section{Effects of AFEs on protein diversity and functional modulation}

To study the biological implications of the alternative use of first exons, we examined whether the N-terminal coding regions were altered in AFEs. The N-terminals were considered to be altered when the putative Methionine start codon was located on the alternative first exons of both AFE types.

In type I AFE clusters (mutually exclusive first exons), the most common scenario involved AFE events that produced transcripts with identical ORFs. In these cases, a common downstream exon which contained the translation start site was shared by all gene structures in the cluster. From our data sets, 84 and 79 of AFE clusters in rice and Arabidopsis, respectively, were of this type. Because the protein structure remained unchanged, alterations between tissue or stage specificity were likely to be the main consequences in these cases.

In type II AFE-containing gene clusters, EST-only gene structures and full-length-containing ones often differed from each other by not only the alternative first exons, but also some downstream exons. Therefore, it was possible that the extra sequences in EST-only structures contained putative translational start codons, and consequently produced multiple protein variants. In our data, 213 and 298 type II AFE clusters in rice and Arabidopsis were of such cases, respectively. Most of these alternative start codons led to additional fragments at the $\mathrm{N}$-termini of proteins. However, we identified some rare cases (five in rice and three in Arabidopsis, respectively) where AFEs resulted in 
Chr1

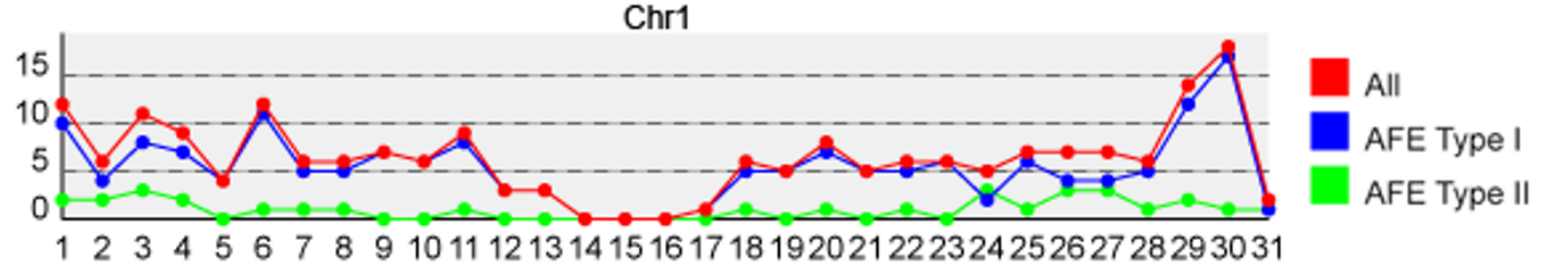

Chr2
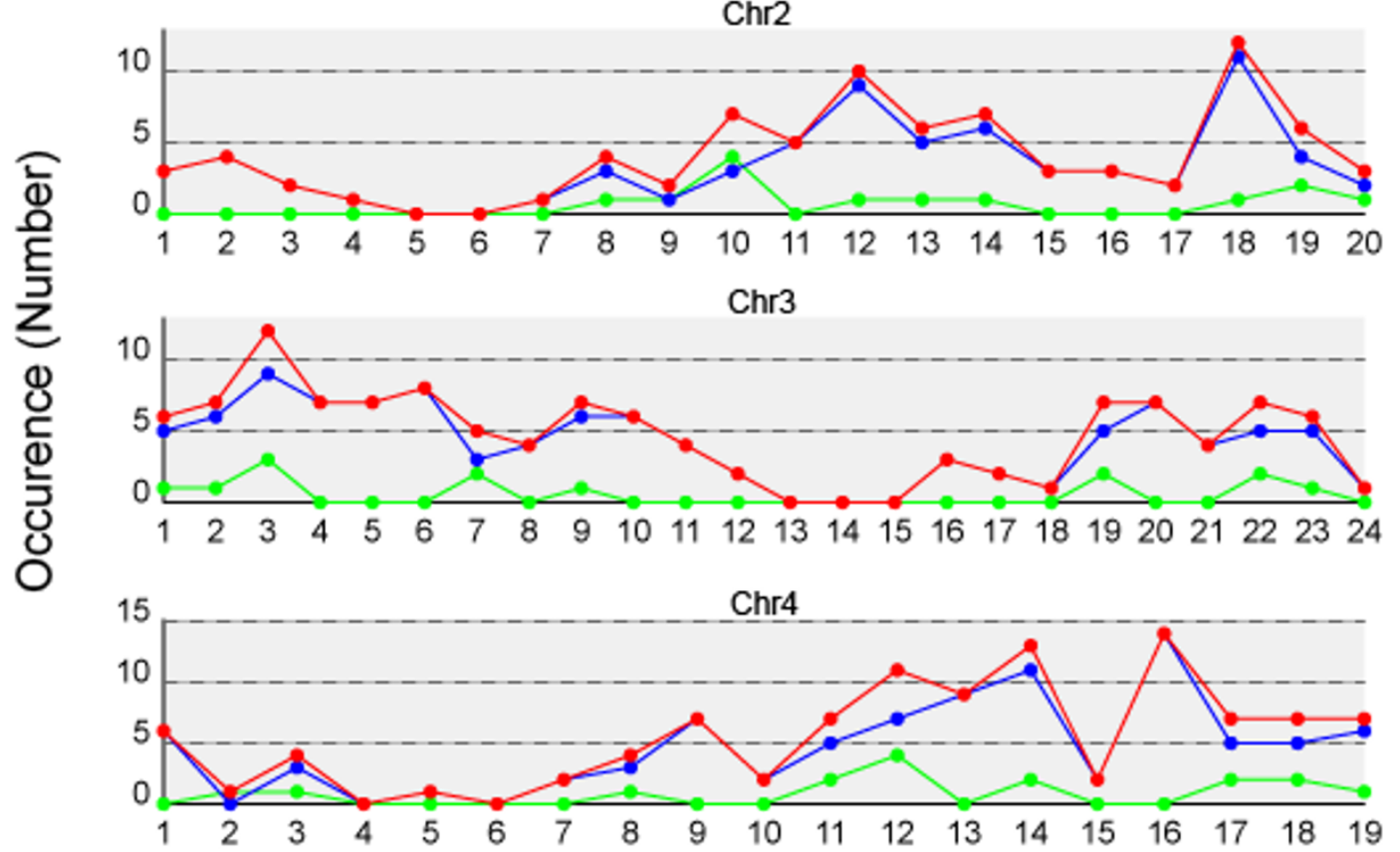

Chr5

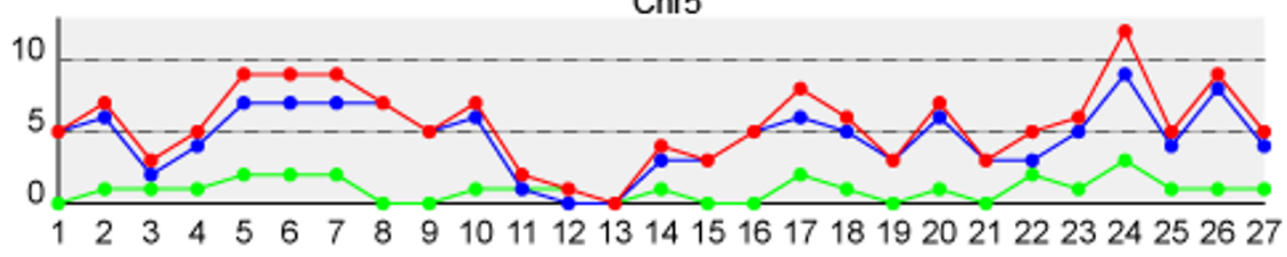

Chromosome Position (M)

\section{Figure 2}

Chromosomal distribution of AFE-containing clusters. The distribution of AFEs on Arabidopsis chromosomes was determined using the alignment positions of AFE-clusters.

multiple reading frames and thereby produced novel proteins.

In total, we identified 266 possible $\mathrm{N}$-terminal changes in rice and 318 in Arabidopsis AFE-containing gene clusters. As shown in Table 2, a strong correlation existed between $\mathrm{N}$-terminal protein changes and the use of putative alternative promoters in type II AFE clusters (as tested using Fisher's Exact Test, $p<0.01)$. It seemed that the distance between gene structures in a cluster contributed significantly to the N-terminal protein changes. Only a small proportion of type I AFE clusters generated protein diversity. The major contributor was the start codon location. We observed no connection between the 5 '-end distance of the gene structures and alternative start codons.

We also investigated the effects of protein $\mathrm{N}$-terminal changes on known functional protein motifs by compar- 
Table 3: 5 ' splice site analysis of AFEs

\begin{tabular}{|c|c|c|c|c|c|c|c|}
\hline & \multirow{2}{*}{$\begin{array}{l}\text { Constitutive } \\
( \pm \text { SD) } *\end{array}$} & \multicolumn{3}{|c|}{ AFE Type I } & \multicolumn{3}{|c|}{ AFE Type II } \\
\hline & & Total & Major** & Minor** & Total & Major** & Minor** \\
\hline Rice & $9.310 \pm 3.72$ & $7.87 \pm 4.11$ & $7.75 \pm 4.23$ & $7.75 \pm 3.91$ & $8.61 \pm 4.01$ & $7.75 \pm 4.03$ & $8.98 \pm 3.20$ \\
\hline Comparison with constitutive sites $* * *$ & & $1.3063 \mathrm{e}-011$ & $5.784 \mathrm{Ie}-007$ & $1.3907 e-006$ & $3.1057 \mathrm{e}-010$ & $1.0233 \mathrm{e}-029$ & 0.9846 \\
\hline Arabidopsis & $8.00 \pm 2.89$ & $7.39 \pm 3.23$ & $8.20 \pm 3.03$ & $5.89 \pm 3.07$ & $8.44 \pm 2.93$ & $8.42 \pm 2.84$ & $8.40 \pm 3.02$ \\
\hline Comparison with constitutive sites $* * *$ & & 0.0013 & 0.4077 & $3.236 \mathrm{le}-012$ & $9.4224 \mathrm{e}-005$ & 0.0062 & 0.0151 \\
\hline
\end{tabular}

* The 5 ' splice site scores were predicted by GeneSplicer. Higher score indicates stronger splicing signal.

** Major and minor types of alternative first exons within each gene cluster were determined as described in the Methods section.

**** $\mathrm{P}$-values were determined using $t$-tests.

ing putative ORF translations of transcript isoforms with the NCBI Conserved Domain Database (CDD) [27]. As shown in Table 2, about $5 \sim 10 \%$ of $\mathrm{N}$-terminal changes in type I AFE clusters overlapped with know functional protein domains in at least one of the isoforms, while 20 30\% of N-terminal changes in type II AFE clusters did so. We found that $\sim 5 \%$ of the functional alterations in type II AFE clusters involved whole domain additions and/or deletions. Such AFE-introduced protein modulation has the potential to result in complex functional regulation.

We noticed that, at least in some cases, the use of alternative first exons was coupled with downstream alternative splicing events (Figure 1C), which probably caused reading frame shifts and rendered the subsequent isoforms possible candidates for nonsense-mediated mRNA decay (NMD). We thus deduced the putative transcription isoforms for gene structures that did not contain full-length/ reference sequences based on the approach from TAP [28]. We used the definition of premature termination codons (PTCs) as in-frame stop codons residing >50 bp upstream of the last 3' exon-exon junction, as previously reported [26]. Screening results indicated that about 284 and 52 of AFE transcription isoforms in rice and Arabidop- sis produced NMD candidates, respectively. These frequencies were much smaller than those observed in the total of plant AS isoforms [26]. This discrepancy might partly result from the fact that AFE-coupled alternative splicing events are only a small subset of the total AS events in plants; it suggests that most of the AFE-containing events are functional, which is consistent with our analysis of the relationship between AFEs and protein diversity.

\section{GO classification of AFE-containing events}

To investigate which kinds of genes were likely to use alternative first exons and what biological consequences AFEs could bring about, we first categorized AFE-containing clusters in rice and Arabidopsis according to the Gene Ontology classification. Then we used the whole genome GO categories from rice and Arabidopsis as references to calculate the probability that a GO category in the AFEcontaining clusters was significantly enriched or depleted. As listed in Tables 5 and 6, although categories of diverse functions were observed, genes participating in enzymatic reactions and cellular processes were significantly enriched in both plants. Enrichment of AFE-containing clusters was also found for the functional categories of cellular process regulation, transporter, ATP binding, cell

Table 4: secondary structure formation analysis at 5' splice sites of AFEs

\begin{tabular}{|c|c|c|c|c|c|c|c|}
\hline & \multirow[t]{2}{*}{ Constitutive $( \pm S D) *$} & \multicolumn{3}{|c|}{ AFE Type I } & \multicolumn{3}{|c|}{ AFE Type II } \\
\hline & & Total & Major** & Minor** & Total & Major** & Minor** \\
\hline Rice & $-19.22 \pm 5.59$ & $-23.61 \pm 8.62$ & $-24.28 \pm 8.37$ & $-23.00 \pm 8.79$ & $-22.45 \pm 7.8$ & $-24.7 \pm 8.51$ & $-20.37 \pm 6.46$ \\
\hline $\begin{array}{l}\text { Comparison with } \\
\text { constitutive sites } * * *\end{array}$ & & $3.2796 \mathrm{e}-07 \mathrm{I}$ & I.8749e-06I & $9.6957 e-035$ & $9.6069 e-082$ & $1.751 \mathrm{le}-160$ & $3.0208 \mathrm{e}-012$ \\
\hline Arabidopsis & $-17.80 \pm 4.33$ & $-15.09 \pm 5.10$ & $-14.59 \pm 5.38$ & $-15.60 \pm 4.62$ & $-16.52 \pm 4.98$ & $-16.47 \pm 4.89$ & $-16.46 \pm 5.29$ \\
\hline $\begin{array}{l}\text { Comparison with } \\
\text { constitutive sites } * * *\end{array}$ & & $1.671 \mathrm{le}-028$ & $4.5892 \mathrm{e}-022$ & $|.3987 e-0| \mid$ & $4.7938 \mathrm{e}-015$ & $1.9863 \mathrm{e}-009$ & $2.9444 \mathrm{e}-009$ \\
\hline
\end{tabular}

\footnotetext{
* Secondary structure formation was measured as Minimal Folding Energy (MFE) by MRNAFOLD. Lower scores indicate a higher likelihood of an input sequence to form a secondary structure;

** Major and minor types of alternative first exons within each gene cluster were determined as described in the Methods section.

**** P-values were determined using t-tests.
} 
Table 5: Functional categories (GO) significantly biased in AFE-containing clusters in Arabidopsis

\begin{tabular}{llll}
\hline & GO category & AFE containing cluster & $P$-value* \\
\hline Enriched** & cellular physiological process & 327 & 0 \\
& metabolism & 297 & 0 \\
nucleotide binding & 65 & 0 & $1.52 \mathrm{E}-10$ \\
& catalytic activity & 27 & $1.35 \mathrm{E}-09$ \\
& transferase activity & 104 & $1.73 \mathrm{E}-08$ \\
& ligase activity & 25 & $1.20 \mathrm{E}-07$ \\
& hydrolase activity & 89 & $1.24 \mathrm{E}-07$ \\
& ubiquitin ligase complex & 13 & $1.94 \mathrm{E}-07$ \\
& intracellular part & 259 & $2.42 \mathrm{E}-07$ \\
& intracellular & 265 & $7.82 \mathrm{E}-06$ \\
& cell part & 368 & $4.80 \mathrm{E}-05$ \\
& membrane part & 37 & 0.000128 \\
& nucleic acid binding & 91 & 0.000265 \\
& lyase activity & 18 & 0.000476 \\
\hline localization & 51 & $5.61 \mathrm{E}-06$ \\
\hline
\end{tabular}

* P-value was calculated by the hypergeometric distribution. The cutoff is IE-5.

** "Enriched" categories refer to those containing significantly more genes (observed) than expected. "Depleted" categories refer to those containing significantly less genes (observed) than expected.

communication, and response to endogenous stimulus in rice. These results indicate that the complex transcription regulation mediated by AFEs might be indispensable for the adaptation to dynamic changes in the external and internal environments of plant cells. It appears plausible that when the environment changes, protein functions are fine-tuned by the addition and/or deletion of functional motifs at the N-termini, or protein localizations are reassigned by altering signal peptides or transporter activities.

Several GO categories showed inconsistency between rice and Arabidopsis (Figure 3). For example, "intracellular part", "intracellular" and "cell part" were enriched in Arabidopsis, but were reduced in rice. Further studies are needed to elucidate such discrepancies.

We also compared functional differences between the two types of AFEs in rice and Arabidopsis. As shown in Figure 4, although there were differences in categories that contained only a few genes, such as "envelope", "molecular transducer activity" and "reproduction", none of these was statistically significant (Fisher's Exact Test $p<0.05$ ). Thus, we concluded that there were no significant functional biases between type I and type II AFE clusters in rice and Arabidopsis.

One should note that at least one disadvantage of using GO classification is that GO mappings of identical gene products from different databases are sometime different, and so the results should be used with a certain degree of caution.

\section{Tissue- and development stage- specific expression of AFE} isoforms in plant genomes

We adopted a method suggested by Qiang Xu et al. [5] to evaluate whether AFEs were involved in tissue- and/or developmental stage-specific expression. Tissue and developmental stage information were downloaded from the NCBI Library Browser classification. For those libraries with ambiguous or incomplete information in the Unigene database, we checked their dbEST entries and classified them accordingly. Then we calculated three scores for each AFE-containing gene, namely a tissue specificity score TS and two robustness values $r \mathrm{TS}$ and $r \mathrm{TS}$. As shown in Table 7, by using High Confidence criteria (HC, see Methods), we identified 390 and 31 AFE clusters involved in tissue-specific expression, as well as 273 and 44 AFE clusters involved in development-stage-specific expression, in rice and Arabidopsis, respectively. With slightly less stringent criteria (Low Confidence, LC, see Methods), the numbers of specifically expressed genes increased two to three-fold.

In total, we estimated that around $20 \sim 66 \%$ of rice AFE clusters were regulated in an either tissue- or development-specific transcription manner. Our results are consistent with a previous report that AFEs are involved in tissue-specific transcription in rice [14]. Conversely, in Arabidopsis, we found only $5 \sim 18 \%$ of AFE-containing clus- 
Table 6: Functional categories (GO) significantly biased in AFE-containing clusters in Rice.

\begin{tabular}{|c|c|c|c|}
\hline Enriched & GO category & AFE containing cluster & $P$-value \\
\hline & metabolism & 468 & 0 \\
\hline & cellular physiological process & 595 & 0 \\
\hline & nucleotide binding & 155 & 0 \\
\hline & hydrolase activity & 144 & 0 \\
\hline & transferase activity & $|3|$ & 0 \\
\hline & oxidoreductase activity & 79 & 0 \\
\hline & ion binding & 65 & 0 \\
\hline & nucleic acid binding & 147 & I.02E-14 \\
\hline & helicase activity & 17 & $2.78 \mathrm{E}-09$ \\
\hline & catalytic activity & 45 & I.04E-08 \\
\hline & lyase activity & 24 & $1.95 \mathrm{E}-08$ \\
\hline & regulation of cellular process & 50 & $3.95 \mathrm{E}-08$ \\
\hline & regulation of physiological process & 50 & 4.25E-08 \\
\hline & non-membrane-bound organelle & 35 & $4.98 \mathrm{E}-08$ \\
\hline & ligase activity & 32 & $6.29 \mathrm{E}-08$ \\
\hline & ATPase activity, coupled to movement of substances & 20 & 7.0IE-08 \\
\hline & organelle part & 35 & 7.38E-08 \\
\hline & intracellular organelle part & 35 & 7.38E-08 \\
\hline & membrane & 208 & I.32E-07 \\
\hline & carrier activity & 27 & $2.15 \mathrm{E}-07$ \\
\hline & membrane part & 32 & I.24E-06 \\
\hline & protein binding & 26 & $1.66 \mathrm{E}-06$ \\
\hline & ion transporter activity & 23 & 2.67E-06 \\
\hline & ribonucleoprotein complex & 23 & $1.38 \mathrm{E}-05$ \\
\hline & microtubule associated complex & 7 & $2.78 \mathrm{E}-05$ \\
\hline & cell communication & 22 & $3.91 \mathrm{E}-05$ \\
\hline & amine binding & 6 & $4.49 \mathrm{E}-05$ \\
\hline & protein transporter activity & 9 & 0.000192 \\
\hline & response to endogenous stimulus & 13 & 0.000197 \\
\hline & unlocalized protein complex & 5 & 0.000212 \\
\hline & cofactor binding & 6 & 0.000212 \\
\hline & ATP-binding cassette (ABC) transporter complex & 7 & 0.000245 \\
\hline & ubiquitin ligase complex & 18 & 0.000306 \\
\hline & nuclear pore & 3 & 0.000338 \\
\hline \multirow[t]{5}{*}{ Depleted } & membrane-bound organelle & 860 & I.47E-52 \\
\hline & intracellular organelle & 878 & $9.04 \mathrm{E}-47$ \\
\hline & intracellular part & 905 & $4.36 \mathrm{E}-39$ \\
\hline & intracellular & 911 & 7.83E-38 \\
\hline & cell part & 1,004 & $2.46 \mathrm{E}-33$ \\
\hline
\end{tabular}

ters to be expressed specifically in certain tissues and/or developmental stages.

\section{Evolutionary conservation of AFEs in plant genomes}

To study the conservation of AFE events between rice and Arabidopsis, we used the longest reference gene or fulllength cDNA in each AFE cluster as representative sequence. Ortholog relationships were identified by applying Inparanoid [24] to these sequences. To our surprises, only 19 AFE-containing gene pairs from rice and Arabidopsis were classified as orthologous groups, which accounted for only $1.4 \%$ of all AFE-containing gene clusters in rice and 2.9\% in Arabidopsis. As shown in Figure 3, GO categories of AFE-containing gene clusters showed no biases between rice and Arabidopsis (Fisher's Exact Test, $p<$ $0.05)$, indicating that evolutionary conservation exists in functional categories instead of individual genes in plant genomes.

\section{Conclusion}

Based on our large scale general 5'-EST and full length cDNA alignments to the genomes of rice and Arabidopsis, we estimated that at least $~ 5 \%$ of expressed geneclusters in plants use alternative first exons. We further analyzed statistical features of these alternatively spliced exons and compared them with that of constitutively spliced exons. The results indicated that there could be more differences between AFEs from rice and Arabidopsis than generally 
Table 7: Tissue- and development stage- specific expression of AFEs in rice and Arabidopsis

\begin{tabular}{lllll}
\hline & & Tissue specific* & Development stage specific* & Both \\
\hline Rice & HC** & 390 & 273 & 200 \\
& LC** & 914 & 713 & 624 \\
Arabidopsis & HC & 31 & 44 & 21 \\
& LC & 55 & 113 & 39 \\
\hline
\end{tabular}

* Tissue- and development stage- specific gene expression were determined using the methods suggested by Qiang $\mathrm{Xu}$ et al.

** High confidence $(\mathrm{HC})$ tissue specificity was defined as TS > 50, $r \mathrm{TS}>0.9$ and $r \mathrm{TS} \sim>0.9$, low confidence (LC) was defined as TS>0, $r$ TS $>0.5$ and $r$ TS >0.5 (see Methods)

anticipated. Expression analysis revealed that 20 66\% of rice AFE clusters were regulated in either tissue- or development- specific manner, which was consistent with a previous report [14]. However, only 5 18\% of Arabidopsis AFE clusters were involved in tissue- or development- specific expression. Although the GO classification of the AFE-containing clusters showed no functional biases between rice and Arabidopsis, only 19 groups of orthologous AFE-containing clusters were identified between the two plants. Considering that monocot and dicot plants may use different splicing machineries which are not completely compatible $[29,30]$, we suggest that AFE events may have evolved independently after the separation of dicot and monocot lineages.

Although some of the AFE events were removed by nonsense-mediated mRNA decay (NMD), which constitutes an mRNA surveillance system, we found that the proportion of NMD coupled AFE events was much lower than that of the total set of alternative splicing evens in plants. Therefore AFE events appear particularly likely to create biologically functional transcription isoforms. Unlike a previous report [14], we have shown that the $49 \%$ and $19 \%$ of AFE events from Arabidopsis and rice affected the

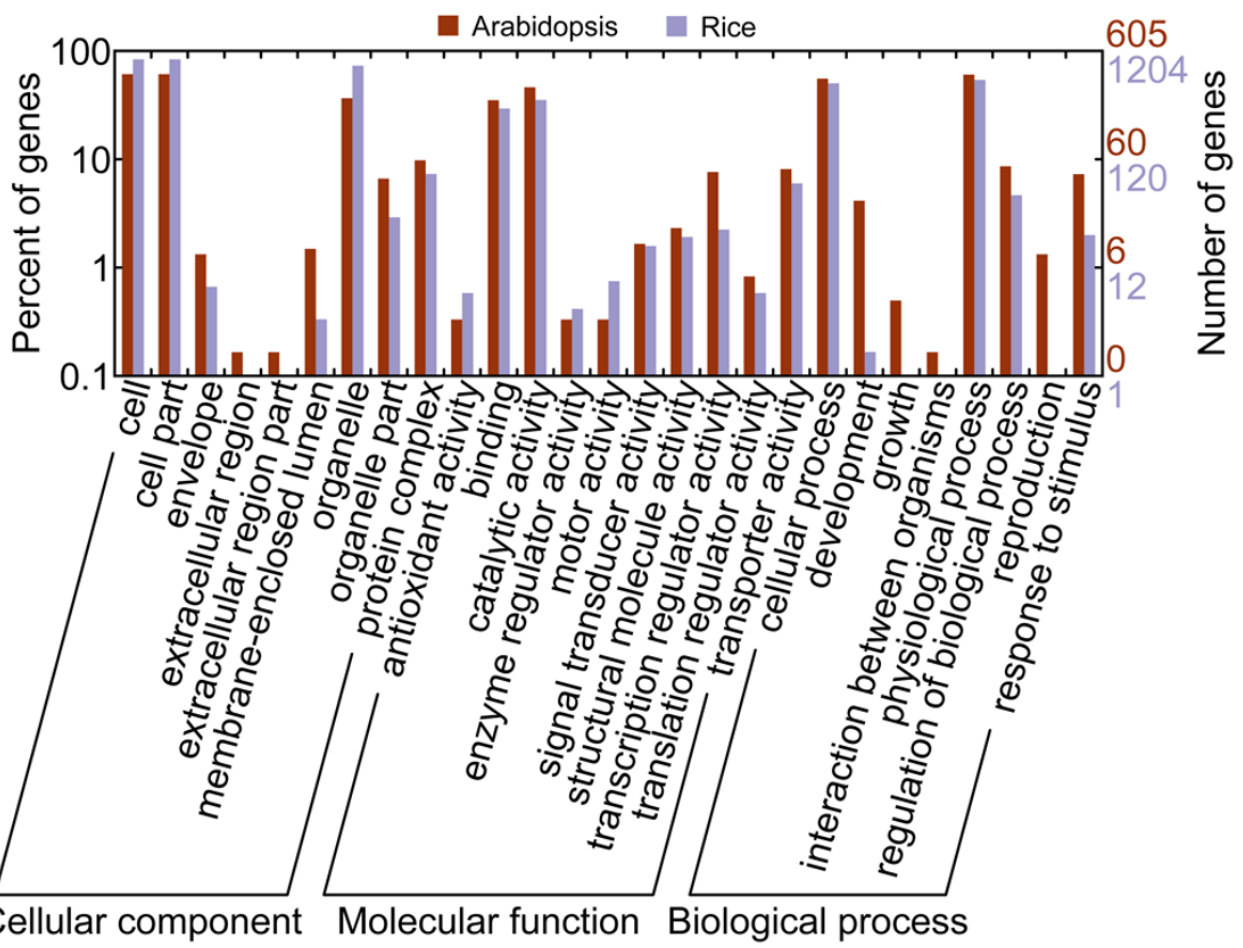

Figure 3

Gene Ontology (GO) categories of AFE-containing clusters in rice and Arabidopsis. The genes were functionally categorized according to the Gene Ontology Consortium and level two of the assignment results were plotted here. $87 \%$ (I,204 of a total I,378) AFE-containing clusters from rice and 94\% (605 of a total 645) AFE clusters from Arabidopsis were classified by GO. 
A

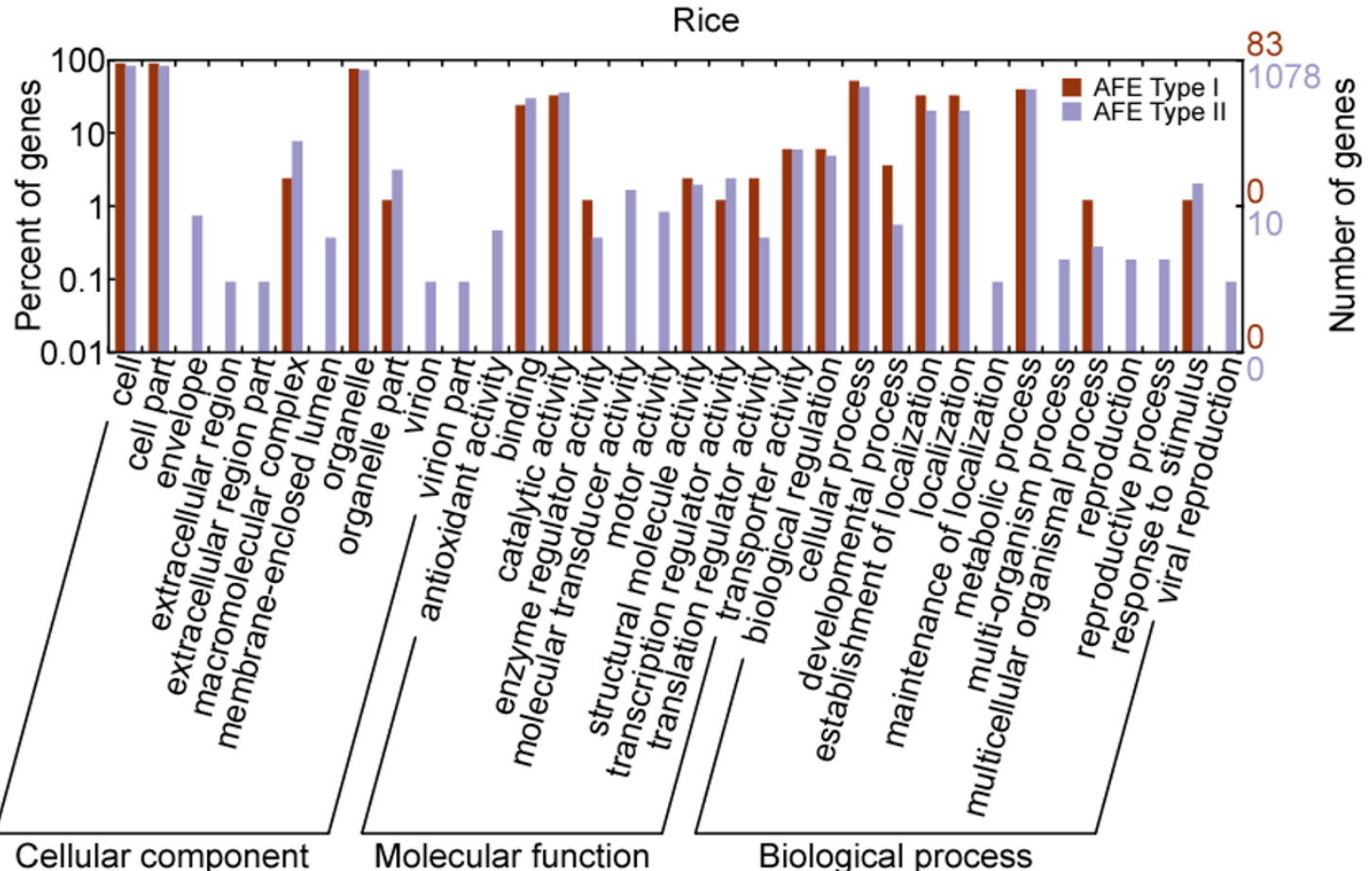

B
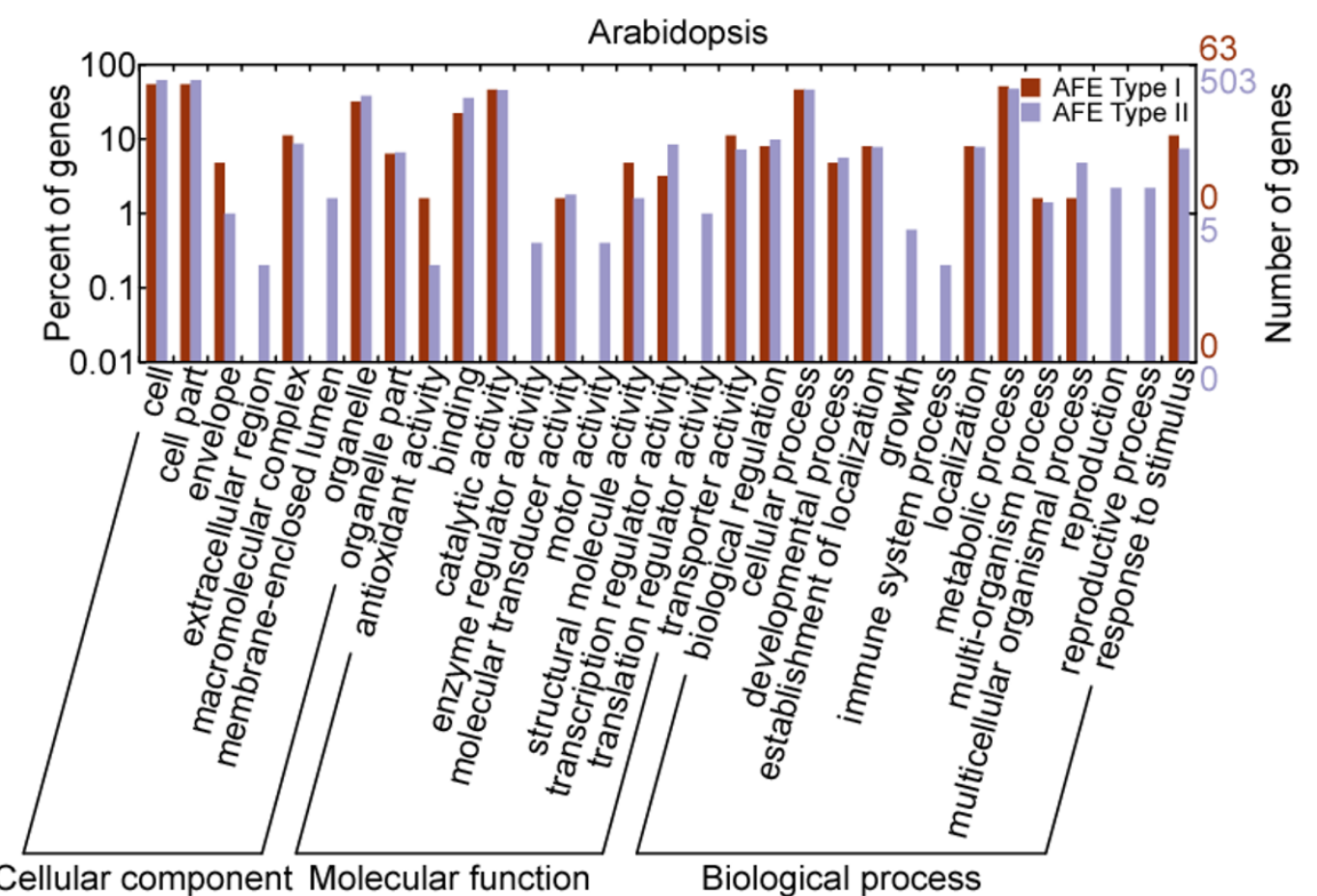

Figure 4

Gene Ontology (GO) categories of two types of AFE-containing clusters in rice and Arabidopsis. The genes were functionally categorized according to the Gene Ontology Consortium and level two of the assignment results were plotted here. GO categories of two types of AFE-containing clusters were plotted for rice (A) and Arabidopsis (B), respectively. 
$\mathrm{N}$-terminal protein sequences, and approximately $23 \%$ of rice and $57 \%$ of Arabidopsis AFE events may derive from the alternative use of multiple promoters. We anticipate that further studies of the relationship between AFEs and protein diversity in vivo will greatly enrich our knowledge about the complexity of gene expression regulation.

All analysis tools, database dumps and detailed description of methods are available upon requests, correspondence should be addressed to HuSN.

\section{Competing interests}

The author(s) declares that there are no competing interests.

\section{Authors' contributions}

SNH and WHC conceived the study. LvCY and CQZ collected the data and performed the statistical analysis. LvGT and WHC controlled and analyzed the data, and drafted the manuscript. All authors read and approved the final manuscript.

\section{Additional material}

\section{Additional file 1}

Chromosomal distribution of AFE-containing clusters in rice genome. The distribution of AFEs on rice chromosomes was determined using the alignment positions of AFE-clusters.

Click here for file

[http://www.biomedcentral.com/content/supplementary/14712229-7-55-S1.png]

\section{Acknowledgements}

We thank BingBing Wang for sharing his Alternative Splicing analysis software and giving other important instructions. The National Natural Science Foundation (NNSF) of China (No. 90208029, to HuSN) supported this work.

\section{References}

I. Blencowe BJ: Alternative splicing: new insights from global analyses. Cell 2006, I 26(I):37-47.

2. Maniatis T, Tasic B: Alternative pre-mRNA splicing and proteome expansion in metazoans. Nature 2002, 418(6894):236-243.

3. Lareau LF, Green RE, Bhatnagar RS, Brenner SE: The evolving roles of alternative splicing. Curr Opin Struct Biol 2004, I 4(3):273-282.

4. Lander ES, Linton LM, Birren B, Nusbaum C, Zody MC, Baldwin J, Devon K, Dewar K, Doyle M, FitzHugh W, Funke R, Gage D, Harris K, Heaford A, Howland J, Kann L, Lehoczky J, LeVine R, McEwan P, McKernan K, Meldrim J, Mesirov JP, Miranda C, Morris W, Naylor J, Raymond C, Rosetti M, Santos R, Sheridan A, Sougnez C, StangeThomann N, Stojanovic N, Subramanian A, Wyman D, Rogers J, Sulston J, Ainscough R, Beck S, Bentley D, Burton J, Clee C, Carter N, Coulson A, Deadman R, Deloukas P, Dunham A, Dunham I, Durbin R, French L, Grafham D, Gregory S, Hubbard T, Humphray S, Hunt A, Jones M, Lloyd C, McMurray A, Matthews L, Mercer S, Milne S, Mullikin JC, Mungall A, Plumb R, Ross M, Shownkeen R, Sims S, Waterston RH, Wilson RK, Hillier LW, McPherson JD, Marra MA, Mardis ER, Fulton LA, Chinwalla AT, Pepin KH, Gish WR, Chissoe SL, Wendl MC, Delehaunty KD, Miner TL, Delehaunty A, Kramer JB,
Cook LL, Fulton RS, Johnson DL, Minx PJ, Clifton SW, Hawkins T, Branscomb E, Predki P, Richardson P, Wenning S, Slezak T, Doggett $\mathrm{N}$, Cheng JF, Olsen A, Lucas S, Elkin C, Uberbacher E, Frazier M, Gibbs RA, Muzny DM, Scherer SE, Bouck JB, Sodergren EJ, Worley KC, Rives CM, Gorrell JH, Metzker ML, Naylor SL, Kucherlapati RS, Nelson DL, Weinstock GM, Sakaki Y, Fujiyama A, Hattori M, Yada T, Toyoda A, Itoh T, Kawagoe C, Watanabe H, Totoki Y, Taylor T, Weissenbach J, Heilig R, Saurin W, Artiguenave F, Brottier P, Bruls T, Pelletier E, Robert C, Wincker P, Smith DR, Doucette-Stamm L, Rubenfield M, Weinstock K, Lee HM, Dubois J, Rosenthal A, Platzer M, Nyakatura G, Taudien S, Rump A, Yang H, Yu J, Wang J, Huang G, Gu J. Hood L, Rowen L, Madan A, Qin S, Davis RW, Federspiel NA, Abola AP, Proctor MJ, Myers RM, Schmutz J, Dickson M, Grimwood J, Cox DR, Olson MV, Kaul R, Raymond C, Shimizu N, Kawasaki K, Minoshima S, Evans GA, Athanasiou M, Schultz R, Roe BA, Chen F, Pan H, Ramser J, Lehrach H, Reinhardt R, McCombie WR, de la Bastide M, Dedhia N, Blocker H, Hornischer K, Nordsiek G, Agarwala R, Aravind L, Bailey JA, Bateman A, Batzoglou S, Birney E, Bork P, Brown DG, Burge CB, Cerutti L, Chen HC, Church D, Clamp M, Copley RR, Doerks T, Eddy SR, Eichler EE, Furey TS, Galagan J, Gilbert JG, Harmon C, Hayashizaki Y, Haussler D, Hermjakob $H$, Hokamp K, Jang W, Johnson LS, Jones TA, Kasif S, Kaspryzk A, Kennedy S, Kent W], Kitts P, Koonin EV, Korf I, Kulp D, Lancet D, Lowe TM, McLysaght A, Mikkelsen T, Moran JV, Mulder N, Pollara VJ, Ponting CP, Schuler G, Schultz J, Slater G, Smit AF, Stupka E, Szustakowski J, Thierry-Mieg D, Thierry-Mieg J, Wagner L, Wallis J, Wheeler R, Williams A, Wolf YI, Wolfe KH, Yang SP, Yeh RF, Collins F, Guyer MS, Peterson J, Felsenfeld A, Wetterstrand KA, Patrinos A, Morgan MJ, de Jong P, Catanese JJ, Osoegawa K, Shizuya H, Choi S, Chen YJ: Initial sequencing and analysis of the human genome. Nature 200I, 409(6822):860-92I.

5. Xu Q, Modrek B, Lee C: Genome-wide detection of tissue-specific alternative splicing in the human transcriptome. Nucl Acids Res 2002, 30(17):3754-3766.

6. Kimura K, Wakamatsu A, Suzuki Y, Ota T, Nishikawa T, Yamashita R, Yamamoto J, Sekine M, Tsuritani K, Wakaguri H, Ishii S, Sugiyama T, Saito K, Isono Y, Irie R, Kushida N, Yoneyama T, Otsuka R, Kanda K, Yokoi T, Kondo H, Wagatsuma M, Murakawa K, Ishida S, Ishibashi T, Takahashi-Fujii A, Tanase T, Nagai K, Kikuchi H, Nakai K, Isogai T, Sugano S: Diversification of transcriptional modulation: largescale identification and characterization of putative alternative promoters of human genes. Genome research 2006, 16(I):55-65

7. Luzi L, Confalonieri S, Di Fiore PP, Pelicci PG: Evolution of Shc functions from nematode to human. Curr Opin Genet Dev 2000, I0(6):668-674.

8. Zavolan M, van Nimwegen E, Gaasterland T: Splice variation in mouse full-length cDNAs identified by mapping to the mouse genome. Genome research 2002, 12(9): 1377-1385.

9. Landry JR, Mager DL, Wilhelm BT: Complex controls: the role of alternative promoters in mammalian genomes. Trends Genet 2003, 19 (II):640-648.

10. Bonham K, Ritchie SA, Dehm SM, Snyder K, Boyd FM: An alternative, human SRC promoter and its regulation by hepatic nuclear factor-I alpha. J Biol Chem 2000, 275(48):37604-376I I.

II. Kelner MJ, Bagnell RD, Montoya MA, Estes LA, Forsberg L, Morgenstern R: Structural organization of the microsomal glutathione S-transferase gene (MGSTI) on chromosome I $2 \mathrm{pl}$ |3.113.2. Identification of the correct promoter region and demonstration of transcriptional regulation in response to oxidative stress. J Biol Chem 2000, 275 (I 7): I 3000-1 3006.

12. Hu ZZ, Zhuang L, Meng J, Leondires M, Dufau ML: The human prolactin receptor gene structure and alternative promoter utilization: the generic promoter hPIII and a novel human promoter hP(N). J Clin Endocrinol Metab 1999, 84(3): I I53-I I 56.

13. Wang $X$, Su H, Bradley A: Molecular mechanisms governing Pcdh-gamma gene expression: evidence for a multiple promoter and cis-alternative splicing model. Genes Dev 2002, 16(15): 1890-1905.

14. Kitagawa N, Washio T, Kosugi S, Yamashita T, Higashi K, Yanagawa H, Higo K, Satoh K, Ohtomo Y, Sunako T, Murakami K, Matsubara K, Kawai J, Carninci P, Hayashizaki Y, Kikuchi S, Tomita M: Computational analysis suggests that alternative first exons are involved in tissue-specific transcription in rice (Oryza sativa). Bioinformatics (Oxford, England) 2005, 2 I (9): I758-1763. 
15. Quelle DE, Zindy F, Ashmun RA, Sherr Cl: Alternative reading frames of the INK4a tumor suppressor gene encode two unrelated proteins capable of inducing cell cycle arrest. Cell 1995, 83(6):993-1000.

16. Liang $\mathrm{H}$, Landweber LF: A genome-wide study of dual coding regions in human alternatively spliced genes. Genome research 2006, 16(2):190-196.

17. Bai X, Peirson BN, Dong F, Xue C, Makaroff CA: Isolation and characterization of SYNI, a RAD2I-like gene essential for meiosis in Arabidopsis. Plant Cell I999, I I(3):417-430.

18. Bairoch A, Apweiler R, Wu CH, Barker WC, Boeckmann B, Ferro S, Gasteiger E, Huang H, Lopez R, Magrane M, Martin MJ, Natale DA, O'Donovan C, Redaschi N, Yeh LSL: The Universal Protein Resource (UniProt). Nucl Acids Res 2005, 33(suppl_I):D I54-I 59.

19. Pertea M, Lin X, Salzberg SL: GeneSplicer: a new computational method for splice site prediction. Nucleic acids research 200I, 29(5): I I85-II90.

20. Ivo LH, Walter F, Peter FS, Bonhoeffer LS, Manfred T, Pet: Fast Fold ing and Comparison of RNA Secondary Structures. Santa Fe Institute; 1993.

21. Bailey TL, Elkan C: Fitting a mixture model by expectation maximization to discover motifs in biopolymers. Proc Int Conf Intell Syst Mol Biol I994, 2:28-36.

22. Ashburner M, Ball CA, Blake JA, Botstein D, Butler H, Cherry JM, Davis AP, Dolinski K, Dwight SS, Eppig JT, Harris MA, Hill DP, IsselTarver L, Kasarskis A, Lewis S, Matese JC, Richardson JE, Ringwald M, Rubin GM, Sherlock G: Gene ontology: tool for the unification of biology. The Gene Ontology Consortium. Nature genetics 2000, 25(I):25-29.

23. Ye J, Fang L, Zheng $H$, Zhang Y, Chen J, Zhang Z, Wang J, Li S, Li R, Bolund L, Wang J: WEGO: a web tool for plotting GO annotations. Nucleic acids research 2006, 34(Web Server issue):W293-7.

24. O'Brien KP, Remm M, Sonnhammer EL: Inparanoid: a comprehensive database of eukaryotic orthologs. Nucleic acids research 2005, 33(Database issue):D476-80.

25. Rice P, Longden I, Bleasby A: EMBOSS: the European Molecular Biology Open Software Suite. Trends Genet 2000, 16(6):276-277.

26. Wang BB, Brendel V: Genomewide comparative analysis of alternative splicing in plants. Proc Natl Acad Sci U S A 2006, 103(18):7175-7|80.

27. Marchler-Bauer A, Anderson JB, Cherukuri PF, DeWeese-Scott C, Geer LY, Gwadz M, He S, Hurwitz DI, Jackson JD, Ke Z, Lanczycki CJ, Liebert CA, Liu C, Lu F, Marchler GH, Mullokandov M, Shoemaker BA, Simonyan V, Song JS, Thiessen PA, Yamashita RA, Yin J], Zhang D, Bryant SH: CDD: a Conserved Domain Database for protein classification. Nucleic acids research 2005, 33(Database issue):D192-6.

28. Kan Z, Rouchka EC, Gish WR, States DJ: Gene Structure Prediction and Alternative Splicing Analysis Using Genomically Aligned ESTs. Genome Res 200I, I I(5):889-900.

29. Goodall G], Filipowicz W: Different effects of intron nucleotide composition and secondary structure on pre-mRNA splicing in monocot and dicot plants. The EMBO journal I991, I0(9):2635-2644.

30. Simpson GG, Filipowicz W: Splicing of precursors to mRNA in higher plants: mechanism, regulation and sub-nuclear organisation of the spliceosomal machinery. Plant molecular biology |996, 32(I-2): |-4|
Publish with Bio Med Central and every scientist can read your work free of charge

"BioMed Central will be the most significant development for disseminating the results of biomedical research in our lifetime. "

Sir Paul Nurse, Cancer Research UK

Your research papers will be:

- available free of charge to the entire biomedical community

- peer reviewed and published immediately upon acceptance

- cited in PubMed and archived on PubMed Central

- yours - you keep the copyright

Submit your manuscript here:

http://www.biomedcentral.com/info/publishing_adv.asp
BioMedcentral 